\title{
An Electrophysiologist Perspective on Risk Stratification in Heart Failure: Can Better Understanding of the Condition of the Cardiac Sympathetic Nervous System Help?
}

\author{
Rasmus Borgquist ${ }^{1,2}$ and Jagmeet P. Singh ${ }^{1}$ \\ ${ }^{I}$ Cardiac Arrhythmia Service, Massachusetts General Hospital, Harvard Medical School, Boston, Massachusetts; and ${ }^{2}$ Arrhythmia \\ Clinic, Lund University, Skaine University Hospital, Lund, Sweden
}

\begin{abstract}
Heart failure is often complicated by arrhythmias that can adversely affect the quality of life and increase the risk for sudden cardiac death. Current risk stratification strategies for sudden cardiac death in the heart failure patient are not ideal, with much potential for further refinement. Overactivation of the sympathetic nervous system has been shown to be associated with worsening heart failure as well as arrhythmic events. Recent advances in our understanding of the autonomic nervous system and new methods for quantification of the pathologic activation of the sympathetic nerves have triggered increasing interest in this field. This viewpoint focuses on the need for and challenges of risk stratification of sudden death in the heart failure patient and discusses the potential value of measuring sympathetic nervous system activity to better stratify risk and to select patients with heart failure for implantable cardioverter defibrillator therapy.
\end{abstract}

Key Words: cardiology (clinical); autonomic defibrillator; sudden death

J Nucl Med 2015; 56:59S-64S

DOI: 10.2967/jnumed.114.148452

\section{O}

udden cardiac death (SCD) is still the leading cause of death in the developed world, claiming up to 450,000 lives per year in the United States alone $(1,2)$. Despite huge efforts to improve the outcomes, including public education in resuscitation and the widespread use of automatic external defibrillators, survival rates for out-of-hospital cardiac arrest are still dismal $(3,4)$. Up to $80 \%$ of patients who have SCD have some degree of underlying coronary artery disease, but only around $20 \%$ will have actual pathologic evidence of acute myocardial necrosis (5), and only about one third of sudden cardiac arrest survivors will develop enzymatic evidence of myocardial infarction (6). Many of these patients may have triggers other than acute myocardial ischemia for their cardiac arrest, and between $10 \%$ and $20 \%$ of victims of SCD have dilated cardiomyopathy as the only underlying structural heart disease (7). However, high-risk patients with significant structural heart disease constitute a small minority of the total number of patients who

\footnotetext{
Received Dec. 15, 2014; revision accepted Mar. 4, 2015.

For correspondence or reprints contact: Jagmeet P. Singh, Cardiac Arrhythmia Service, Cardiology Division, Massachusetts General Hospital, 55 Fruit St., Boston, MA 02114-2750.

E-mail: jsingh@mgh.harvard.edu.

COPYRIGHT (C 2015 by the Society of Nuclear Medicine and Molecular Imaging, Inc.
}

experience malignant arrhythmias every year (8). Approximately $50 \%-60 \%$ of SCDs occur in the general population who have no significant heart disease; and even for those who have SCD and underlying structural heart disease, in up to $50 \%$ of the cases, sudden death is the first manifestation of disease $(9,10)$.

Heart failure is a common disease that imposes a significant reduction in the quality of life and life expectancy for the individual patient and an increasing financial burden on the health care system (11). It is well known that patients with heart failure are at increased risk of SCD and ventricular arrhythmias, and a large body of evidence has indicated that patients with reduced left ventricular systolic ejection fraction $(\leq 35 \%)$ are at greatest risk $(12-15)$. In the Framingham heart study, patients with heart failure were 6-9 times more likely to have SCD than the general population (16). Interestingly, the mode of death correlates with the symptom class of heart failure: patients with mild to moderate symptoms are more likely to experience SCD, whereas patients with severe symptoms are more likely to die from pump failure (17). Hence, in the group of patients with severe heart failure (i.e., New York Heart Association class IV), the overall prognosis is poor, and the use of an implantable cardioverter defibrillator (ICD) is less likely to significantly prolong life; but in the group with moderate heart failure (New York Heart Association II and III), the risk of SCD is substantially higher and an ICD is more likely to be beneficial. Despite this crude, subjective classification of heart failure, there remains a paucity of risk stratification strategies that may help ferret out the patient with a reduced left ventricular ejection fraction (LVEF) who may benefit from an ICD.

\section{RISK STRATIFICATION}

\section{The Need}

One of the most important tasks for risk stratification in this context is the appropriate selection of patients who are at such a high risk of ventricular arrhythmias that they will benefit significantly from an ICD. It is well established that ICDs can successfully treat most ventricular arrhythmia episodes, thereby preventing a cardiac arrest from transforming into an SCD, but the treatment is costly from a health economics perspective (18), and it comes with a significant risk of potentially serious complications $(19,20)$. Furthermore, on examination of the Multicenter Automatic Defibrillator Implantation Trial (MADIT II) (18) study data during the first 3 y after implantation, about $70 \%$ of the ICD-treated patients in a heart failure population with primary prophylactic ICDs will never need their device, $20 \%$ will die from heart failure anyway, and only $10 \%$ will be saved by their ICD. Even in the group of patients with adequate ICD therapy, not all arrhythmic events 
would have resulted in SCD if left untreated by the ICD. The occurrence of self-limiting episodes of ventricular tachycardia detected by the device may falsely indicate that the benefit regarding prevention of SCD is higher than it actually may seem. Indeed, with more conservative programming and delayed therapy up to $60 \mathrm{~s}$ after the initiation of ventricular tachycardia, such as in the MADIT-RIT (Reduction in Inappropriate Therapy) trial, the number of patients who were in need of appropriate ICD therapy during a 1.4-y follow-up was only $8 \%$, indicating that most patients in fact did not have sustained malignant arrhythmias (21).

The only consistently reproducible selection criterion for primary prophylactic ICD treatment in the heart failure population so far has been reduced ejection fraction $(<30 \%-35 \%)$, but it is widely acknowledged that this selection method is far from perfect $(13,15,22-24)$. For instance, the Multicenter Unsustained Tachycardia Trial (MUSTT) showed that patients whose only risk factor was an ejection fraction of $30 \%$ or less had a 2-y arrhythmic risk of less than 5\% (25). On the other hand, SCD still does occur in some patients with heart failure who may currently not qualify for ICD therapy (i.e., LVEF > 35\%); clearly, a more refined selection tool would fill a clinical need in this area. A reflection of the uncertainty regarding the selection criteria can also be derived from the fact that $22 \%$ of all ICDs in the United States are implanted on the basis of indications that do not meet guideline-based criteria (26). Hence, although clinical electrophysiologists believe that ICDs are sometimes underused for those patients who really need them, the general perception may be that the health care system allows too many ICDs in patients who never actually need them. This then reinforces the need for a risk stratification strategy to solve the two key problems plaguing the field-namely, identification of low-risk patient subsets within the existing group of ICD-treated patients and identification of high-risk patient subsets outside the currently accepted criteria for ICD treatment. If imaging of the autonomic nervous system could enhance the risk stratification for high- or low-risk patients, that information could be incorporated into our current risk stratification schemes; and the combined information should then be used and tested in prospective randomized clinical trials comparing ICD intervention with optimal medical therapy.

\section{The Challenges}

Risk stratification of arrhythmias has always been challenging, especially because life-threatening rhythm disorders are dynamic events involving several variables. Looking at this simplistically, the minimum requirements for an arrhythmia to manifest typically include a trigger, a willing cardiac substrate, and a modulator such as the autonomic tone. The substrate is reflective of the underlying structural heart disease, such as scar or fibrosis in ischemic or dilated cardiomyopathy, or an inherent ion-channel disorder (e.g., long QT syndrome or Brugada syndrome). Arrhythmia triggers are acute events (e.g., electrolyte disturbances, myocardial ischemia, stress, or alcohol) that work in conjunction with the modulator (e.g., altered neurohormonal balance or pathologic activation of the autonomic nervous system in heart failure) that serves to perpetuate the arrhythmia once it is set in motion.

It is well known that increased sympathetic activity can be associated with arrhythmias and SCD and that increased parasympathetic activity can act protectively (27-29). Therefore, altered autonomic balance is increasingly recognized as an important factor in arrhythmogenesis; and in fact, the status of the cardiac autonomic nervous system can be implicated in all 3 major pathways that are believed to contribute to the initiation and perpetuation of lethal arrhythmias (Fig. 1). Cardiac denervation or innervation perfusion mismatch within a particular cardiac region can provide the autonomic substrate for a reentrant arrhythmia (30). An increased sympathetic activation and pathologic neurohormonal activation of the renin-angiotensin-aldosterone system (as seen in heart failure) can then provide the environment that is needed for the continuation of arrhythmias; and, finally, an altered sympathetic and parasympathetic nervous system balance promotes the occurrence of early afterdepolarizations and premature ventricular beats that can act as the crucial arrhythmia trigger. Thus, knowing the patient's autonomic profile, in addition to other clinical variables, can be key to understanding an individual's risk of SCD.

Several risk stratifiers for SCD have been evaluated over the years (Table 1). In addition to traditional risk factors for coronary heart disease and significant comorbidity such as renal failure and diabetes, these stratifiers include, first, ventricular function (measured by LVEF evaluation by echocardiography, multigated acquisitions, or cardiovascular MR imaging); second, arrhythmias (Holter-electrocardiography [ECG] or implantable loop-recorders); third, electrical markers of substrates for arrhythmias (signal-averaged ECG and electrophysiology study); fourth, surface ECG variables such as T-wave alternans and QT dispersion; fifth, autonomic function (heart rate variability, heart rate turbulence, baroreflex sensitivity, and so forth); sixth, other more rarely used modalities for autonomic function such as blood sampling of norepinephrine spillover, microneurography, and vascular reactivity; and seventh, recently, the quantification of autonomic cardiac innervation (sympathetic nerve terminals) by a ${ }^{123}$ I-metaiodobenzylguanidine (MIBG) or PET scan. Additionally, several risk score algorithms and risk stratification strategies have been published that try to pinpoint which patients in the population identified by guidelines actually benefit from ICD therapy (31-33). In addition to lacking the appropriate sensitivity and specificity for life-threatening arrhythmias, no risk scoring system has been prospectively evaluated as a selection strategy for device therapy.

Among the available risk stratifications, depressed left ventricular systolic function is a well-established risk factor for SCD in larger

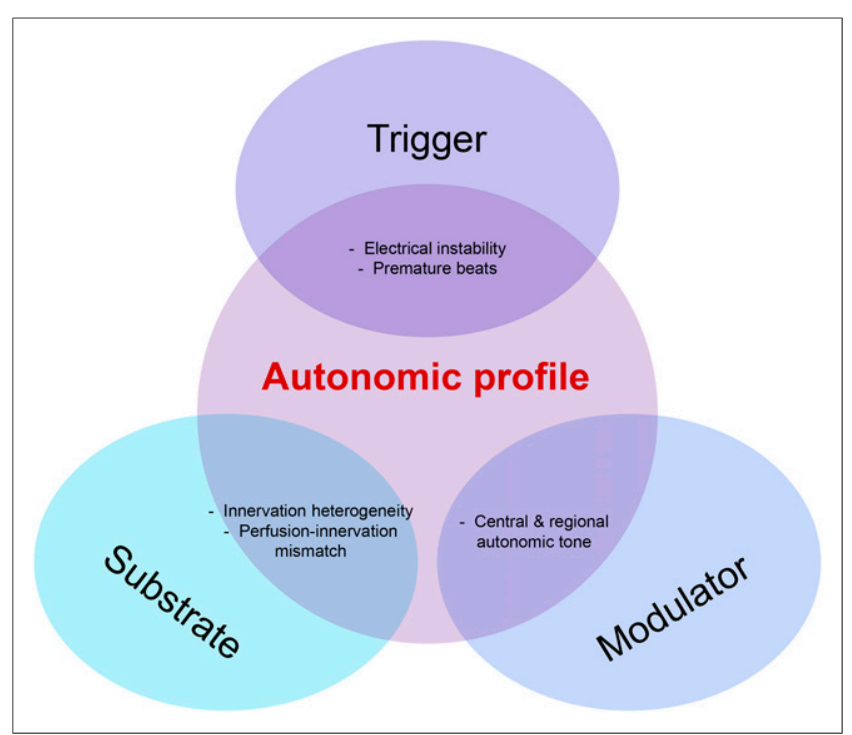

FIGURE 1. Mechanism of arrhythmia: importance of the autonomic profile. 
TABLE 1

Risk Stratification Strategies for Prediction of Sudden Cardiac Death in Patients with Heart Failure

\begin{tabular}{|c|c|}
\hline Category & Details \\
\hline Traditional risk factors for coronary heart disease & $\begin{array}{l}\text { Diabetes, age, sex, blood pressure, blood lipid levels, presence } \\
\text { of diabetes mellitus, cigarette smoking, and so forth }\end{array}$ \\
\hline $\begin{array}{l}\text { Clinical comorbidities in patients already treated with } \\
\text { an implantable defibrillator }\end{array}$ & $\begin{array}{l}\text { Atrial fibrillation, widened QRS duration, age, renal insufficiency, } \\
\text { diabetes, and so forth }\end{array}$ \\
\hline \multicolumn{2}{|l|}{ Family history of sudden cardiac death } \\
\hline \multirow[t]{2}{*}{ Ventricular function } & Reduced ejection fraction (echocardiography) \\
\hline & Fibrosis/infarction (cardiac MR imaging) \\
\hline Arrhythmias & Nonsustained VT/sustained VT (long-term ECG recordings) \\
\hline \multirow[t]{2}{*}{ Electrical markers of substrates for arrhythmias } & Late potentials (signal-averaged ECG) \\
\hline & Inducible arrhythmia (programmed electrical stimulation) \\
\hline \multirow[t]{3}{*}{ Surface ECG-derived markers for electrical instability } & T-wave alternans \\
\hline & QT dispersion/QT interval \\
\hline & Left bundle branch block \\
\hline \multirow[t]{4}{*}{ Autonomic function } & Norepinephrine spillover \\
\hline & Heart rate variability \\
\hline & Heart rate turbulence \\
\hline & Baroreflex sensitivity \\
\hline \multirow[t]{2}{*}{ Cardiac autonomic imaging } & 123I-MIBG SPECT scan \\
\hline & ${ }^{11} \mathrm{C}-\mathrm{HED}$ PET scan \\
\hline
\end{tabular}

cohorts, but it is hampered by a low predictive accuracy for the individual patient, as discussed previously. Data on myocardial scarring (evaluated by CMR) have the ability to predict the occurrence of ventricular arrhythmias (34), but a major limitation of CMR until now has been that it is expensive, requires considerable expertise, and is contraindicated for patients with ICDs. In retrospective studies, the technique seems promising, and total scar burden has been shown to correlate with arrhythmias in ICD-treated patients, but prospective randomized trials are lacking thus far (35,36). Microvolt T-wave alternans is derived noninvasively from a Holter monitor or high-fidelity electrocardiographic recordings during exercise and has been prospectively evaluated as a risk predictor in patients receiving ICDs, with variable results (37-41). Heart rate variability (HRV) evaluated using a Holter monitor is also noninvasive and readily accessible in most centers. It describes the variation in heart rate from beat to beat and can be represented in several ways, including a time domain and a frequency domain. The results can give information on the sympathovagal balance; a reduced HRV corresponds to impaired autonomic balance. HRV has been shown to provide prognostic information in addition to clinical data in an unselected population of patients with heart failure (42), and a reduced HRV is associated with a higher risk of SCD (43). All these investigative tools, although contributing to better understanding of either the substrate or the modulator, have lacked a sufficient positive predictive value to become mainstream selection strategies. Additionally, recent publications have highlighted the need for standardized testing in a setting that is likely to yield the best predictive value for the outcome of the test-for example, different types of autonomic response to stress testing or other tests that are easily obtained and can be readily interpreted (44).

\section{SYMPATHETIC IMAGING: IS THERE A ROLE?}

Because the autonomic nervous system can set off the trigger, influence the substrate, and perpetuate the arrhythmia, an investigative modality to better image and understand sympathetic nervous system activity seems quite fitting. Although approved for several years in European countries, the adoption of imaging of the sympathetic nervous system activity in heart failure has been limited in the United States. The 2013 approval of radioactive ${ }^{123}$ I-MIBG for imaging in heart failure by the Food and Drug Administration has brought radionuclide imaging of sympathetic innervation of the heart to the forefront again (45). The commonly used radiotracers are ${ }^{123} \mathrm{I}-\mathrm{MIBG}$ for planar and SPECT imaging and ${ }^{11} \mathrm{C}$-hydroxyephedrine for PET imaging. The most accepted measure of heartto-mediastinal $(\mathrm{H} / \mathrm{M})$ ratio can be calculated using either planar imaging (area-based region of interest) or SPECT imaging (volumebased region of interest), as shown in Figure $2(46,47)$.

Several insightful measures can be obtained from ${ }^{123} \mathrm{I}-\mathrm{MIBG}$ SPECT imaging. An assessment of the patient's segmental ${ }^{123} \mathrm{I}-$ MIBG tracer uptake can be made using the 17 left ventricular segments (48), and each myocardial segment is scored on a 5-point tracer uptake scale from 0 , normal tracer uptake, to 4 , no tracer uptake. A ${ }^{123}$ I-MIBG SPECT defect score is then obtained and defined as the summation of all the segmental tracer uptake scores. This score can then be combined with a perfusion technetium SPECT score obtained at the same investigation. By subtracting the perfusion defect score from the ${ }^{123} \mathrm{I}$-MIBG defect score, a size of mismatch is calculated-that is, myocardium with abnormal ${ }^{123}$ I-MIBG uptake but normal perfusion uptake. The reason for the mismatch is most likely that sympathetic nerve fibers are more vulnerable to ischemia 


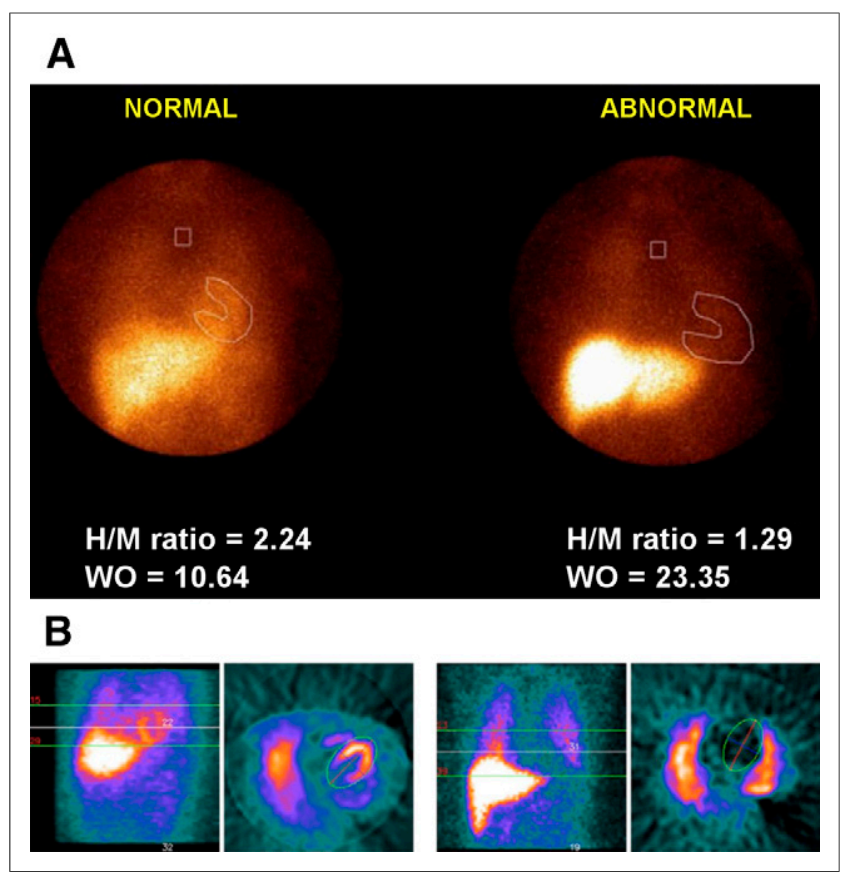

FIGURE 2. $H / M$ ratio in normal heart (left) and heart with reduced cardiac autonomic innervation (right) imaged by planar ${ }^{123}$ I-MIBG scanning (A) and volume-based SPECT 123/-MIBG scanning (B). WO = washout. (Reprinted with permission of $(47,66)$.)

than cardiomyocytes are; thus, the periinfarct region can be partially denervated, but the myocytes are fully viable. This region may then be particularly susceptible to triggering of ventricular arrhythmias and development of reentrant circuits due to innervation supersensitivity in combination with the damaged nerve fibers (49). Similar measures can be obtained using PET, and abnormal patterns of ${ }^{11} \mathrm{C}$-hydroxyephedrine retention have been identified in several groups of patients with ventricular tachycardias, including right ventricular arrhythmias $(50,51)$, Brugada syndrome (52), and congenital long QT syndrome (53).

As mentioned previously, the best-studied modality in heart failure patients is ${ }^{123} \mathrm{I}-\mathrm{MIBG}$ planar imaging. Recently, a systematic review of 18 studies with a total of 1,755 patients evaluated the prognostic impact of ${ }^{123}$ I-MIBG imaging findings in patients with heart failure and found that the H/M ratio was indeed useful for predicting clinical outcome (54). Favorable left ventricular remodeling in heart failure patients has also been shown to correlate with improvement in sympathetic innervation by ${ }^{123}$ I-MIBG imaging; and data support that the changes in innervation are evident before remodeling, which is confirmed by other imaging modalities (5557). There is also increasing evidence that a reduced $\mathrm{H} / \mathrm{M}$ ratio correlates with an increased risk of arrhythmias and that it can provide incremental or better value than other risk stratification tools. In a study by Tamaki et al. (58) of patients with heart failure and an LVEF of $40 \%$ or less, the ${ }^{123}$ I-MIBG washout rate was a better predictor of SCD than other measures of autonomic function (QT dispersion or HRV). Other studies have also shown an independent correlation between SCD, spontaneous or induced malignant arrhythmias, and an abnormal H/M ratio (59-62). Other studies that have sought to investigate the physiology of the relationship have been unable to clearly demonstrate a correlation between the inducibility of ventricular arrhythmia during an electrophysiology study and the standard indices of ${ }^{123} \mathrm{I}-\mathrm{MIBG}$ imaging $(61,63)$.
In the AdreView Myocardial Imaging for Risk Evaluation in Heart Failure (ADMIRE-HF) study (64), the largest prospective study, 961 heart failure patients had an initial ${ }^{123}$ I-MIBG scan performed and were then followed for cardiac events during a median of 17 mo. The results showed that an $\mathrm{H} / \mathrm{M}$ ratio of less than 1.6 was highly predictive of major cardiac adverse events (New York Heart Association functional class progression, potentially life-threatening arrhythmic event, or cardiac death) and ventricular arrhythmia events in a population with symptomatic heart failure and an LVEF of $35 \%$ or less (Fig. 3) (64). Notably, the relationship for H/M ratio and mortality was linear, and mortality ranged from $0 \%$ in the group with an $\mathrm{H} / \mathrm{M}$ ratio of 1.80 to $20 \%$ or more in the group with an $\mathrm{H} / \mathrm{M}$ ratio of less than 1.10. In fact, there may be a role for the prediction of ventricular arrhythmias or SCD in patients who qualify for primary prophylactic ICD treatment (65), because the patients included in the study comprised those meeting criteria for primary prophylactic ICD treatment but without an ICD at the time of inclusion into the study. The investigators found that the independent predictors of arrhythmic events were lower systolic blood pressure (hazard ratio, 1.19 for each 10-point decrease), LVEF less than $25 \%$ (hazard ratio, 1.97), and ${ }^{123} \mathrm{I}-\mathrm{MIBG}-$ derived $\mathrm{H} / \mathrm{M}$ ratio less than 1.6 (hazard ratio, 3.48). These findings, when incorporated into a risk score, were useful in risk-stratifying patients for serious life-threatening arrhythmias (46). It is evident that imaging the sympathetic nervous system may provide additional insight into the myocardial substrate and its vulnerability to arrhythmias.

Ideally, data from imaging the autonomic nervous system should be used to complement existing risk-stratification models for SCD and ventricular arrhythmias. By appropriately quantifying the degree of autonomic dysfunction, these data could be incorporated into summative risk scores. This strategy has the potential to fill gaps of knowledge, especially for patients at increased risk of ventricular arrhythmias who currently fall outside guideline recommendations, such as those with moderately reduced ejection fraction. Another challenging category is patients with low ejection fraction but without any other indicators of increased risk.

However, many gaps remain in our understanding of the autonomic tone within an individual and the implications this may have on the occurrence of life-threatening arrhythmias. Although sympathetic nerve imaging may have the potential to better select patients for

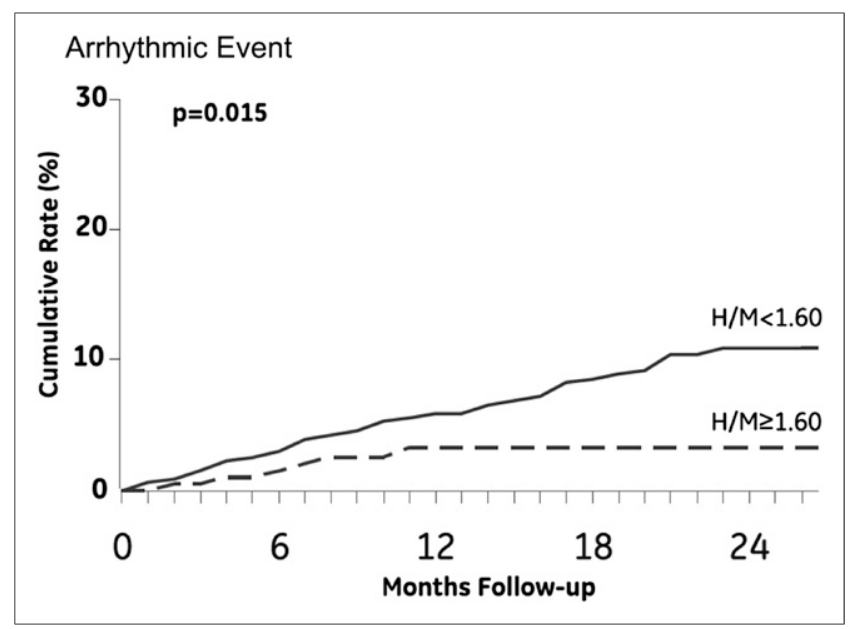

FIGURE 3. Risk of arrhythmic event stratified for $\mathrm{H} / \mathrm{M}$ ratio in ADMIRE-HF study. (Reprinted with permission of (64).) 
device therapy, it is probably the interaction between the extent and distribution of myocardial sympathetic denervation with the central autonomic tone that incites the arrhythmic event. The major challenges in the arena of risk stratification for sudden death include the accurate identification of patients with a low ejection fraction who are at a low risk for arrhythmias and who may not need an ICD, while simultaneously providing recognition of high-risk patients with an LVEF of $35 \%$ or greater who may benefit from an ICD. Understanding the sympathetic nervous system seems like a good next step in stratifying patient risk, but prospective randomized trials will be required before risk stratification can become a mainstream strategy.

\section{DISCLOSURE}

No potential conflict of interest relevant to this article was reported.

\section{REFERENCES}

1. Kong MH, Fonarow GC, Peterson ED, et al. Systematic review of the incidence of sudden cardiac death in the United States. J Am Coll Cardiol. 2011;57:794801.

2. Zheng ZJ, Croft JB, Giles WH, Mensah GA. Sudden cardiac death in the United States, 1989 to 1998. Circulation. 2001;104:2158-2163.

3. Nichol G, Thomas E, Callaway CW, et al. Regional variation in out-of-hospital cardiac arrest incidence and outcome. JAMA. 2008;300:1423-1431.

4. Hallstrom AP, Ornato JP, Weisfeldt M, et al. Public-access defibrillation and survival after out-of-hospital cardiac arrest. N Engl J Med. 2004;351:637646.

5. Farb A, Tang AL, Burke AP, Sessums L, Liang Y, Virmani R. Sudden coronary death: frequency of active coronary lesions, inactive coronary lesions, and myocardial infarction. Circulation. 1995;92:1701-1709.

6. Greene HL. Sudden arrhythmic cardiac death: mechanisms, resuscitation and classification-the Seattle perspective. Am J Cardiol. 1990;65:4B-12B.

7. Deo R, Albert CM. Epidemiology and genetics of sudden cardiac death. Circulation. 2012;125:620-637.

8. Myerburg RJ, Kessler KM, Castellanos A. Sudden cardiac death: structure, function, and time-dependence of risk. Circulation. 1992;85:I2-I10

9. de Vreede-Swagemakers JJ, Gorgels AP, Dubois-Arbouw WI, et al. Out-ofhospital cardiac arrest in the 1990's: a population-based study in the Maastricht area on incidence, characteristics and survival. J Am Coll Cardiol. 1997;30:15001505 .

10. Fishman GI, Chugh SS, Dimarco JP, et al. Sudden cardiac death prediction and prevention: report from a National Heart, Lung, and Blood Institute and Heart Rhythm Society Workshop. Circulation. 2010;122:2335-2348.

11. Go AS, Mozaffarian D, Roger VL, et al. Heart disease and stroke statistics: 2014 update-a report from the American Heart Association. Circulation. 2014;129: e28-e292.

12. Moss AJ, Hall WJ, Cannom DS, et al. Improved survival with an implanted defibrillator in patients with coronary disease at high risk for ventricular arrhythmia: Multicenter Automatic Defibrillator Implantation Trial Investigators. $N$ Engl J Med. 1996;335:1933-1940.

13. Moss AJ, Zareba W, Hall WJ, et al. Prophylactic implantation of a defibrillator in patients with myocardial infarction and reduced ejection fraction. $N$ Engl J Med. 2002;346:877-883

14. Buxton AE, Lee KL, Fisher JD, Josephson ME, Prystowsky EN, Hafley G. A randomized study of the prevention of sudden death in patients with coronary artery disease: Multicenter Unsustained Tachycardia Trial Investigators. N Engl J Med. 1999;341:1882-1890.

15. Bardy GH, Lee KL, Mark DB, et al. Amiodarone or an implantable cardioverterdefibrillator for congestive heart failure. N Engl J Med. 2005;352:225-237.

16. Kannel WB, Wilson PW, D'Agostino RB, Cobb J. Sudden coronary death in women. Am Heart J. 1998;136:205-212.

17. Effect of metoprolol CR/XL in chronic heart failure: Metoprolol CR/XL Randomised Intervention Trial in Congestive Heart Failure (MERIT-HF). Lancet. 1999;353:2001-2007.

18. Zwanziger J, Hall WJ, Dick AW, et al. The cost effectiveness of implantable cardioverter-defibrillators: results from the Multicenter Automatic Defibrillator Implantation Trial (MADIT)-II. J Am Coll Cardiol. 2006;47:2310-2318.
19. Alter P, Waldhans S, Plachta E, Moosdorf R, Grimm W. Complications of implantable cardioverter defibrillator therapy in 440 consecutive patients. Pacing Clin Electrophysiol. 2005;28:926-932.

20. Haines DE, Wang Y, Curtis J. Implantable cardioverter-defibrillator registry risk score models for acute procedural complications or death after implantable cardioverter-defibrillator implantation. Circulation. 2011;123:2069-2076.

21. Moss AJ, Schuger C, Beck CA, et al. Reduction in inappropriate therapy and mortality through ICD programming. N Engl J Med. 2012;367:2275-2283.

22. Myerburg RJ, Reddy V, Castellanos A. Indications for implantable cardioverterdefibrillators based on evidence and judgment. J Am Coll Cardiol. 2009;54:747763.

23. Myerburg RJ. Implantable cardioverter-defibrillators after myocardial infarction. N Engl J Med. 2008;359:2245-2253.

24. Passman R, Kadish A. Shouldn't everyone have an implantable cardioverterdefibrillator? Circulation. 2009;120:2166-2167.

25. Buxton AE, Lee KL, Hafley GE, et al. Limitations of ejection fraction for prediction of sudden death risk in patients with coronary artery disease: lessons from the MUSTT study. J Am Coll Cardiol. 2007;50:1150-1157.

26. Al-Khatib SM, Hellkamp A, Curtis J, et al. Non-evidence-based ICD implantations in the United States. JAMA. 2011;305:43-49.

27. Vanoli E, De Ferrari GM, Stramba-Badiale M, Hull SS Jr, Foreman RD, Schwartz PJ. Vagal stimulation and prevention of sudden death in conscious dogs with a healed myocardial infarction. Circ Res. 1991;68:1471-1481.

28. Lown B, Verrier RL. Neural activity and ventricular fibrillation. $N$ Engl J Med. 1976;294:1165-1170.

29. Schwartz PJ, La Rovere MT, Vanoli E. Autonomic nervous system and sudden cardiac death: experimental basis and clinical observations for post-myocardial infarction risk stratification. Circulation. 1992;85:I77-I91.

30. Sasano T, Abraham MR, Chang KC, et al. Abnormal sympathetic innervation of viable myocardium and the substrate of ventricular tachycardia after myocardial infarction. J Am Coll Cardiol. 2008;51:2266-2275.

31. Chan PS, Nallamothu BK, Spertus JA, et al. Impact of age and medical comorbidity on the effectiveness of implantable cardioverter-defibrillators for primary prevention. Circ Cardiovasc Qual Outcomes. 2009;2:16-24.

32. Barsheshet A, Moss AJ, Huang DT, McNitt S, Zareba W, Goldenberg I. Applicability of a risk score for prediction of the long-term (8-year) benefit of the implantable cardioverter-defibrillator. J Am Coll Cardiol. 2012;59:2075-2079.

33. Goldenberg I, Vyas AK, Hall WJ, et al. Risk stratification for primary implantation of a cardioverter-defibrillator in patients with ischemic left ventricular dysfunction. J Am Coll Cardiol. 2008;51:288-296.

34. Gao P, Yee R, Gula L, et al. Prediction of arrhythmic events in ischemic and dilated cardiomyopathy patients referred for implantable cardiac defibrillator: evaluation of multiple scar quantification measures for late gadolinium enhancement magnetic resonance imaging. Circ Cardiovasc Imaging. 2012;5:448-456.

35. Scott PA, Rosengarten JA, Murday DC, et al. Left ventricular scar burden specifies the potential for ventricular arrhythmogenesis: an LGE-CMR study. J Cardiovasc Electrophysiol. 2013;24:430-436.

36. Roes SD, Borleffs CJ, van der Geest RJ, et al. Infarct tissue heterogeneity assessed with contrast-enhanced MRI predicts spontaneous ventricular arrhythmia in patients with ischemic cardiomyopathy and implantable cardioverterdefibrillator. Circ Cardiovasc Imaging. 2009;2:183-190.

37. Monasterio V, Martinez JP, Laguna P, et al. Prognostic value of average T-wave alternans and QT variability for cardiac events in MADIT-II patients. J Electrocardiol. 2013;46:480-486.

38. Madias JE. Re: High amplitude T-wave alternans precedes spontaneous ventricular tachycardia or fibrillation in ICD electrograms [letter]. Heart Rhythm. 2008;5:e4-e5; author reply, e6.

39. De Ferrari GM, Sanzo A. T-wave alternans in risk stratification of patients with nonischemic dilated cardiomyopathy: can it help to better select candidates for ICD implantation? Heart Rhythm. 2009;6(suppl):S29-S35.

40. Chow T, Kereiakes DJ, Bartone C, et al. Microvolt T-wave alternans identifies patients with ischemic cardiomyopathy who benefit from implantable cardioverterdefibrillator therapy. J Am Coll Cardiol. 2007;49:50-58.

41. Costantini O, Hohnloser SH, Kirk MM, et al. The ABCD (Alternans Before Cardioverter Defibrillator) Trial: strategies using T-wave alternans to improve efficiency of sudden cardiac death prevention. J Am Coll Cardiol. 2009;53:471479.

42. Tsuji H, Larson MG, Venditti FJ Jr, et al. Impact of reduced heart rate variability on risk for cardiac events: The Framingham Heart Study. Circulation. 1996;94:2850-2855.

43. La Rovere MT, Pinna GD, Maestri R, et al. Short-term heart rate variability strongly predicts sudden cardiac death in chronic heart failure patients. Circulation. 2003;107:565-570. 
44. Wellens HJ, Schwartz PJ, Lindemans FW, et al. Risk stratification for sudden cardiac death: current status and challenges for the future. Eur Heart J. 2014;35:1642-1651.

45. Gupta S, Amanullah A. Radionuclide imaging of cardiac sympathetic innervation in heart failure: unlocking untapped potential. Heart Fail Rev. 2015;20:215226.

46. Chen J, Garcia EV, Galt JR, Folks RD, Carrio I. Optimized acquisition and processing protocols for I-123 cardiac SPECT imaging. J Nucl Cardiol. 2006;13:251260.

47. Chen J, Folks RD, Verdes L, Manatunga DN, Jacobson AF, Garcia EV. Quantitative I-123 mIBG SPECT in differentiating abnormal and normal mIBG myocardial uptake. J Nucl Cardiol. 2012;19:92-99.

48. Cerqueira MD, Weissman NJ, Dilsizian V, et al. Standardized myocardial segmentation and nomenclature for tomographic imaging of the heart: a statement for healthcare professionals from the Cardiac Imaging Committee of the Council on Clinical Cardiology of the American Heart Association. Circulation. 2002;105:539-542.

49. Minardo JD, Tuli MM, Mock BH, et al. Scintigraphic and electrophysiological evidence of canine myocardial sympathetic denervation and reinnervation produced by myocardial infarction or phenol application. Circulation. 1988;78:1008-1019.

50. Wichter T, Schafers M, Rhodes CG, et al. Abnormalities of cardiac sympathetic innervation in arrhythmogenic right ventricular cardiomyopathy: quantitative assessment of presynaptic norepinephrine reuptake and postsynaptic beta-adrenergic receptor density with positron emission tomography. Circulation. 2000;101:15521558.

51. Schäfers M, Lerch H, Wichter $\mathrm{T}$, et al. Cardiac sympathetic innervation in patients with idiopathic right ventricular outflow tract tachycardia. J Am Coll Cardiol. 1998;32:181-186.

52. Kies $\mathrm{P}$, Wichter T, Schafers $\mathrm{M}$, et al. Abnormal myocardial presynaptic norepinephrine recycling in patients with Brugada syndrome. Circulation. 2004;110:30173022 .

53. Mazzadi AN, Andre-Fouet X, Duisit J, et al. Cardiac retention of ${ }^{11} \mathrm{C}-\mathrm{HED}$ in genotyped long QT patients: a potential amplifier role for severity of the disease. Am J Physiol Heart Circ Physiol. 2003;285:H1286-H1293.

54. Verberne HJ, Brewster LM, Somsen GA, van Eck-Smit BL. Prognostic value of myocardial ${ }^{123}$ I-metaiodobenzylguanidine (MIBG) parameters in patients with heart failure: a systematic review. Eur Heart J. 2008;29:1147-1159.

55. Kasama S, Toyama T, Sumino H, et al. Additive effects of spironolactone and candesartan on cardiac sympathetic nerve activity and left ventricular remodeling in patients with congestive heart failure. J Nucl Med. 2007;48:1993-2000.
56. Kasama S, Toyama T, Hatori $\mathrm{T}$, et al. Effects of intravenous atrial natriuretic peptide on cardiac sympathetic nerve activity and left ventricular remodeling in patients with first anterior acute myocardial infarction. J Am Coll Cardiol. 2007;49:667-674

57. Fukuoka S, Hayashida K, Hirose Y, et al. Use of iodine-123 metaiodobenzylguanidine myocardial imaging to predict the effectiveness of beta-blocker therapy in patients with dilated cardiomyopathy. Eur J Nucl Med. 1997;24:523-529.

58. Tamaki S, Yamada T, Okuyama Y, et al. Cardiac iodine-123 metaiodobenzylguanidine imaging predicts sudden cardiac death independently of left ventricular ejection fraction in patients with chronic heart failure and left ventricular systolic dysfunction: results from a comparative study with signal-averaged electrocardiogram, heart rate variability, and QT dispersion. J Am Coll Cardiol. 2009;53:426-435.

59. Nagahara D, Nakata T, Hashimoto A, et al. Predicting the need for an implantable cardioverter defibrillator using cardiac metaiodobenzylguanidine activity together with plasma natriuretic peptide concentration or left ventricular function. J Nucl Med. 2008;49:225-233.

60. Agostini D, Verberne HJ, Burchert W, et al. I-123-mIBG myocardial imaging for assessment of risk for a major cardiac event in heart failure patients: insights from a retrospective European multicenter study. Eur J Nucl Med Mol Imaging. 2008;35:535-546.

61. Boogers MJ, Borleffs CJ, Henneman MM, et al. Cardiac sympathetic denervation assessed with 123-iodine metaiodobenzylguanidine imaging predicts ventricular arrhythmias in implantable cardioverter-defibrillator patients. $J$ Am Coll Cardiol. 2010;55:2769-2777.

62. Kasama S, Toyama T, Sumino H, et al. Prognostic value of serial cardiac ${ }^{123}$ IMIBG imaging in patients with stabilized chronic heart failure and reduced left ventricular ejection fraction. $J$ Nucl Med. 2008;49:907-914.

63. Bax JJ, Kraft O, Buxton AE, et al. ${ }^{123}$ I-mIBG scintigraphy to predict inducibility of ventricular arrhythmias on cardiac electrophysiology testing: a prospective multicenter pilot study. Circ Cardiovasc Imaging. 2008;1:131-140.

64. Jacobson AF, Senior R, Cerqueira MD, et al. Myocardial iodine-123 metaiodobenzylguanidine imaging and cardiac events in heart failure: results of the prospective ADMIRE-HF (AdreView Myocardial Imaging for Risk Evaluation in Heart Failure) study. J Am Coll Cardiol. 2010;55:2212-2221.

65. Al Badarin FJ, Wimmer AP, Kennedy KF, Jacobson AF, Bateman TM. The utility of ADMIRE-HF risk score in predicting serious arrhythmic events in heart failure patients: incremental prognostic benefit of cardiac ${ }^{123}$ I-mIBG scintigraphy. J Nucl Cardiol. 2014;21:756-762.

66. Ji SY, Travin MI. Radionuclide imaging of cardiac autonomic innervation. J Nucl Cardiol. 2010;17:655-666. 